\title{
Nonverbal Emotion Recognition and Performance: Differences Matter Differently
}

William H. Bommer

Bryan J. Pesta

b.pesta@csuohio.edu

Susan F. Storrud-Barnes

Cleveland State University, s.f.barnes@csuohio.edu

Follow this and additional works at: https://engagedscholarship.csuohio.edu/bus_facpub

Part of the Organizational Behavior and Theory Commons

How does access to this work benefit you? Let us know!

Publisher's Statement

This article is (c) Emerald Group Publishing and permission has been granted for this version to appear here: http://www.emeraldinsight.com/doi/full/10.1108/02683941111099600. Emerald does not grant permission for this article to be further copied/distributed or hosted elsewhere without the express permission from Emerald Group Publishing Limited.

\section{Original Published Citation}

Bommer, W. H., Pesta, B. J., Storrud-Barnes, S. F. (2011). Nonverbal Emotion Recognition and Performance: Differences Matter Differently. Journal of Managerial Psychology, 26(1), pp. 28-41.

This Article is brought to you for free and open access by the Monte Ahuja College of Business at EngagedScholarship@CSU. It has been accepted for inclusion in Business Faculty Publications by an authorized administrator of EngagedScholarship@CSU. For more information, please contact library.es@csuohio.edu. 


\title{
Nonverbal emotion recognition and performance: differences matter differently
}

\author{
William H. Bommer \\ Department of Management, Craig School of Business, \\ California State University, Fresno, California, USA, and \\ Bryan J. Pesta and Susan F. Storrud-Barnes \\ Department of Management and Labor Relations, Nance College of Business, \\ Cleveland State University, Cleveland, Ohio, USA
}

\begin{abstract}
Purpose - This paper aims to explore and test the relationship between emotion recognition skill and assessment center performance after controlling for both general mental ability (GMA) and conscientiousness. It also seeks to test whether participant sex or race moderated these relationships. Design/methodology/approach - Using independent observers as raters, the paper tested 528 business students participating in a managerial assessment center, while they performed four distinct activities of: an in-basket task; a team meeting for an executive hiring decision; a team meeting to discuss customer service initiatives; and an individual speech.

Findings - Emotion recognition predicted assessment center performance uniquely over both GMA and conscientiousness, but results varied by race. Females were better at emotion recognition overall, but sex neither was related to assessment center performance nor moderated the relationship between it and emotion recognition. The paper also found that GMA moderated the emotion recognition/assessment performance link, as the former was important to performance only for people with low levels of GMA.

Practical implications - The results seem to contradict those who argue that E-IQ is an unqualified predictor of performance. Emotional recognition is not uniformly valuable; instead, it appears to benefit some groups more than others.

Originality/value - The paper clarifies the emotional intelligence literature by providing further support for the predictive validity of emotion recognition in performance contexts, and by separating out how emotional recognition benefits certain population groups more.
\end{abstract}

Keywords Sex and gender issues, Performance management, Individual psychology, Emotional intelligence, Assessment centres

Paper type Research paper

Emotion recognition and assessment center performance: more than meets the eye (for some).

Research on the importance of emotional intelligence (E-IQ) in work settings is growing rapidly (e.g. Brotheridge and Lee, 2008; Byron, 2008; Fox and Spector, 2000; Riggio and Reichard, 2008; Salovey et al., 2004). E-IQ is the ability to manage the emotions of one's own self and of others (Salovey et al., 2004). The construct is multi-dimensional, and includes managing, understanding, using and perceiving emotions (Mayer and Salovey, 1997). Our focus here is on the latter dimension of E-IQ - perceiving emotions (specifically, non-verbal emotions). 
We focus on whether individual and demographic differences among people might moderate the effects of emotion recognition skill on performance. Specifically, the present study examines whether participant race or sex moderates the relationship between non-verbal emotion recognition and assessment-center performance. In addition, we examine whether nonverbal emotion recognition predicts performance, even after controlling for GMA and personality factors (i.e. conscientiousness). Research to date typically has not controlled for these important individual differences. By doing so here, we hope to provide a clearer picture of the role emotion recognition plays in the performance of complex social and cognitive tasks, while also examining potential demographic moderators of these relationships.

\section{Theoretical background and hypotheses}

Studying nonverbal emotions and their recognition is certainly not new. In fact, Darwin (1872) acknowledged that emotions are instrumental for adaptive behaviors such as triggering the "fight or flight" mechanism, for mate selection and for procreation. Much of the early psychological research on nonverbal emotion recognition focused on identifying differences between individuals who were better or worse at accurately recognizing nonverbal expressions. In general, the early research was not done in organizational settings, nor did it focus on mainstream organizational variables. Results suggested that people who are better at recognizing nonverbal emotional expressions tend to be more interpersonally sensitive, higher in psychological adjustment and more trusting of others (see Sabatelli et al., 1983). They also tend to have more positive interactions with others, and to be more satisfied with their personal relationships (Noller and Feeney, 1994).

In organizational settings, initial work on this topic tended to focus on the "helping professions". Researchers have identified positive links between employees' skill in emotion recognition and job performance ratings for teachers, officers, physicians, counselors and similar occupations (e.g. Campbell et al., 1971). Recent research has focused on the consequences of accurate nonverbal emotion recognition across a relatively, wide range of workplace settings (see, e.g. Rubin et al., 2005).

Current research also suggests that the relationship between emotion recognition and performance is more complex than previously assumed. The relationship seems to vary by occupational type and employee gender. For example, Byron (2008) reported that female (but not male) managers who were better at nonverbal emotion recognition received higher ratings from their subordinates. In contrast, both male and female salespeople benefited from better nonverbal emotion recognition skills. Overall, salespeople who were one standard deviation above the mean at recognizing nonverbal emotional expressions averaged $\$ 1,000$ more in yearly salary increases (Byron, 2008). The relationship between nonverbal emotional decoding and workplace ratings also varies by the valence (i.e. whether positive or negative emotions) and channel (i.e. facial expression, tone of voice, or posture; Elfenbein and Ambady, 2002a) of the emotional expression.

Thus, the relationship between emotion recognition and performance seems to be more nuanced than once believed. While nonverbal emotion recognition skills predict positive outcomes, the strength of the benefit may vary with individual differences on a number of dimensions (e.g. race, sex, personality or GMA). One goal of the current research is to further explore the potentially differential benefits of emotion recognition skills for different people. 
We first consider whether emotion recognition has a unique relationship with work-related performance, even after controlling for general mental ability (GMA) and personality (specifically, conscientiousness).

Second, we examine whether demographic variables (race and sex) moderate these relationships. Third, we explore whether emotion recognition skills can compensate for lower levels of GMA in certain instances.

The optimal setting to test these issues is one where many people perform identical tasks in a tightly controlled environment. In this regard, assessment center data could be ideal. Assessment centers provide a high degree of control, a large sample for detecting potential interactions, and a degree of organizational relevance. The combination of these factors is usually lacking in most organizational field studies. Hence, we report data here on a large sample of business students completing a mandatory assessment as part of their business education.

\section{General mental ability and conscientiousness}

Many studies have found positive relationships between emotion recognition and job performance; however, none to date have simultaneously considered whether these relationships, could be explained, by the employees' GMA and/or personality. If emotion recognition skills truly are important for performance, they need to be evaluated while controlling for other critical individual difference variables. The research shows clearly that both GMA and personality (especially conscientiousness) are related strongly to job performance, and should therefore be controlled when examining the value-added of emotion-recognition skill. For example, GMA is likely the best predictor of job performance across a variety of contexts (see, e.g. Gottfredson, 2003; Judge et al., 2010; Schmidt and Hunter, 1998). Numerous meta-analyses have demonstrated that employees who are more intelligent do better at work (see Hulsheger et al., 2007; Schmidt and Hunter, 1998).

While GMA seems to explain the most variance in job performance, other variables offer incremental validity to prediction accuracy. The best example is perhaps personality. Many different models of personality exist, but the most studied in work settings is the Big 5 model (Costa and McCrae, 1985). In two meta-analyses, the Big 5 trait, conscientiousness, emerged as the best personality factor for predicting job performance across all jobs (Barrick and Mount, 1991; Schmidt and Hunter, 1998). Conscientious people are responsible and dependable, and this trait does not seem to vary much with GMA. In a meta-analysis examining the validity of different criteria used in personnel selection, conscientiousness produced an $18 \%$ increment in validity over GMA alone (Schmidt and Hunter, 1998).

Because GMA and conscientiousness are positively associated with job performance over a wide range of jobs, we felt it critical to control for these variables when investigating whether emotion recognition skills would predict assessment center performance, which to our knowledge has not been done before. Nonetheless, we expect emotion recognition to show incremental validity for several reasons. First, emotion recognition is likely distinct from both GMA and conscientiousness. For example, Nowicki and Duke (1994) reported that although emotion recognition predicted academic achievement, it was unrelated to GMA. Hence, our first hypothesis is as follows:

H1. Emotion recognition skill will be positively related to assessment center performance, even after controlling for GMA and conscientiousness. 


\section{Sex and race}

Early research on nonverbal emotion recognition focused on possible sex differences. Meta-analysis suggests that females acquire emotion recognition skills younger in life, and that their relative advantage in emotion recognition persists into adulthood (McClure, 2000). In addition, sex may have an indirect effect on the relationship between emotion recognition and performance ratings. This effect could be driven by expectations people have about how the sexes differ in their emotion recognition skills. Because women tend to be better at recognizing emotions (Hall, 2008) they may be more sensitive to other's emotional responses as well (e.g. Ruble, 1983).

Some theorists suggest that women have a relative advantage over men in emotion recognition skills because women traditionally have been of lower perceived status than men. The theory of nonverbal behavior supports the notion that lower status individuals need to be more attentive to the emotional displays of others, relative to higher status individuals (Henley, 1977; Kirouac and Hess, 1999). Doing so is believed to afford advantages to those with lower status (Kirouac and Hess, 1999). The need to be attentive to the emotional displays of higher status individuals may arise because these displays can serve to "keep others in their place and allow an individual to gain or recover status” (Heise and O’Brien, 1993). Lower status individuals are expected to observe and recognize the relative higher status of others, and communication about status can be derived from emotional displays.

Because of their perceived lower status in society (e.g. Ridgeway and Diekema, 1992), women may benefit more from accurately recognizing nonverbal emotional expressions that can be used to their advantage. Thus, appeal to status differences suggests that the increased importance of emotion recognition for women may be used to help offset perceived status differences between "lower" and "higher" status work members. Consistent with these arguments, $H 2$ is as follows:

H2. Sex will moderate the relationship between emotion recognition and assessment center performance, such that the relationship will be stronger for women versus men.

In the USA, race and status are inextricably linked, with whites (Caucasians of non-Hispanic descent) generally being afforded the highest status relative to any other racial or ethnic group. Elfenbein and Ambady (2002b) found meta-analytic support for the "subordination hypothesis". The idea is that people lower in status or power would be motivated to better recognize the emotional displays of those with higher status or power (Henley, 1977). In a series of experiments, Snodgrass $(1985,1992)$ found that those assigned lower status roles were generally more sensitive and more able to accurately recognize how persons in higher status roles felt about them. Status differences therefore correlate with accuracy in recognizing others' nonverbal behavior.

We therefore predict that emotion recognition skill will be more beneficial to non-whites than to whites. Indeed, the very notion that lower status individuals will be better at emotion recognition rests on the assumption that an advantage is conferred to lower status individuals who are better skilled:

H3. Race (non-white, white) will moderate the relationship between emotion recognition and assessment center performance, such that the relationship will be stronger for non-whites versus whites. 
Finally, the status arguments presented herein allow us to make a further prediction regarding the potential moderating effect of GMA in the emotion-recognition/assessment center performance link. Perceptions of status also are linked to levels of GMA. Georgesen and Harris (1998) found that people with high status frequently were judged as more competent and intelligent, and better looking than those with low status. Further, the connection between GMA and social status has been supported widely for many years (Judge et al., 2010; Nettle, 2003; Saunders, 2002).

Hence, we expect that people of lower GMA would obtain more benefits from being able to recognize nonverbal emotions than would people of higher GMA. Although we control for GMA in $H 1$, here we test whether it moderates the relationship between emotion recognition and performance:

H4. GMA will moderate the relationship between nonverbal emotion recognition and assessment center performance, such that emotion recognition will be more strongly related to assessment center performance for people with lower GMA than for people with higher GMA.

\section{Methods}

\section{Sample and procedure}

The present sample consisted of 528 undergraduate business students at a Mid-western university who participated in a mandatory behavioral assessment center as a skill-building component of their organizational behavior class. Of the subjects, 55 percent were male. Most participants were white (83 percent), and the remaining students were Asian or Asian American (11 percent), African American (3 percent), Hispanic (1 percent), and other (2 percent). The average age was 20.8 $(\mathrm{SD}=1.9)$ years.

The Iliad Assessment Center includes four distinct activities. These behavioral activity components consisted of:

(1) An in-basket task.

(2) A team meeting for an executive hiring decision.

(3) A team meeting to discuss customer service initiatives.

(4) An individual speech.

All team meetings, and the individual speech, were videotaped for subsequent rating. This process yielded a score for each student on each of the four behavioral activity components.

The raters used for this study were employed by the Iliad Assessment Center, and were blind to the identity of the students (they live in different states and have no personal connection to the students), as well as blind to all experimental conditions. Raters received frame-of-reference training (Bernardin and Buckley, 1981) and rated the students in pairs. Conflicts, between raters, were settled, by reviewing the tapes, and reaching agreement. The raters had an average of one year of rating experience, and routinely rated students using the Iliad Assessment Center. All disputes between raters were settled by consensus, but previous usage has indicated rater agreement in over 95 percent of ratings.

The Iliad assessment center has been validated and used in other published studies, and is discussed in greater detail by Rode et al. (2005, 2007). From the student's 
perspective, the assessment center is 145 minutes long, and is an integrated "day-in-the life" of a management-level position. The raters use behavioral checklists and are trained to reach consensus on the presence, absence, and sometimes magnitude or effectiveness of a series of specific behaviors. Participants also completed a battery of paper and pencil tests, described in the following.

\section{Measures}

\section{Assessment center performance}

Participants were rated on the extent to which they displayed 54 distinct behaviors (see Rode et al., 2007 for the complete list). Each behavior incorporated precisely defined levels based on specific behavioral anchors. Subject matter experts weighted the behaviors to reflect relative importance to overall task effectiveness and standardized scores for the speech and each leaderless group discussion separately. We then summed the activity scores to create the assessment center performance score.

The in-basket task from the assessment center was not used in the main analysis because it did not involve personal interaction, and it is a task where GMA, rather than emotion recognition, was important for success. This distinction, however, allows the score from the in-basket to be used in follow-up analysis to further test the relationship between GMA and emotion recognition.

\section{Emotion recognition skill}

The participants' skill in emotion recognition was assessed using the receptive portion of the Diagnostic Analysis of Nonverbal Accuracy (DANVA2) for adults (Nowicki, 2000). The receptive portion of the DANVA2 (adult form) consists of three sub-tests:

(1) Facial expressions.

(2) Paralanguage.

(3) Postures.

All sub-tests have been used in numerous studies (see Hall, 2008; Nowicki and Duke, 1994; Elfenbein and Ambady, 2002a) with diverse populations, differing in terms of age, gender, racial and cultural background, intelligence, and psychosocial adjustment. All sub-tests have satisfactory reliability and validity (Nowicki, 2000; McClure, 2000).

Because we were interested in a composite of the subscales, we took the scores from each sub-test and converted them to "percentage correct". Then, we took the average of the three percentages to provide a single emotion recognition percentage. This conversion made scores easy to understand (a percentage), weighted the different sub-tests equally, and presented results intuitively (i.e. higher scores equal better performance).

\section{General mental ability}

We measured GMA with the Wonderlic Personnel Test (WPT), a 12-minute, timed test consisting of 50 items, scored as the number of correct responses. Scores on the WPT correlate strongly (range $=0.85$ to 0.93 ) with the Wechsler Adult Intelligence Scale (Dodrill and Warner, 1988). The WPT also possesses strong test-retest reliability and predictive validity (McKelvie, 1989; Pesta and Poznanski, 2009). 


\section{Conscientiousness}

Conscientiousness was measured using five items $(\alpha=0.80)$ from Goldberg's (1999) International Personality Item Pool (IPIP). Sample items included "Pay attention to details" and "Get chores done right away". Respondents were asked to rate how well the behavioral statements described them, using a Likert scale, ranging from " 1 " (very inaccurate) to "5" (very accurate). The IPIP items have been validated against the NEO Five-Factor Inventory (Costa and McCrae, 1985), with average inter-scale correlations of 0.94, when corrected for attenuation due to scale unreliabilities (Goldberg, 1999).

\section{Sex and race}

Participants self-reported their sex as either male (coded 1) or female (coded 0), and their race as either: white (non-Hispanic), Asian or Asian American, African-American, Hispanic, or other. Responses were recoded as either white (1) or non-white (0).

\section{Results}

Table I presents means, standard deviations, and simple correlations between all study variables. All variables were significantly correlated with assessment-center performance except sex $(r=-0.01)$. Correlations ranged from $r=0.09$ for conscientiousness, to $r=0.23$ for intelligence. Importantly, the ability to recognize emotions correlated (albeit weakly, $r=0.14$ ) with assessment center performance.

Hierarchical linear regression was used to test the study hypotheses. Before entering interaction terms into the regression model, the constituent variables were centered using the mean deviation approach (to reduce co-linearity; see, e.g. Aiken and West, 1991). The independent and control variables were entered in two steps. In the first step, the main effects were entered. In the second step, the three interaction terms, emotion recognition by sex, emotion recognition by race, and emotion recognition by GMA were entered. Results appear in Table II.

To test $H 1$, we inspected the regression coefficient for emotion recognition when entered together with the control variables. The regression coefficient was positive, and indicated that emotion recognition was related significantly to assessment center performance $(\beta=0.09, p<0.05)$, as predicted. Emotion recognition showed incremental validity for predicting performance after controlling for general mental ability, conscientiousness, sex and race.

Table I.

Means, standard deviations, and intercorrelations for the study variables

\begin{tabular}{lrrrcccrr}
\hline & Mean & \multicolumn{1}{c}{ SD } & 1 & 2 & 3 & 4 & 5 & 6 \\
\hline AC performance & 481.95 & 51.26 & - & & & & & \\
Emotion recognition & 71.44 & 7.47 & $0.14^{* * *}$ & - & & & \\
General mental ability & 28.85 & 5.07 & $0.23^{* * *}$ & $0.20^{* * *}$ & - & & \\
Conscientiousness & 3.45 & 0.76 & $0.09^{*}$ & $0.11^{* *}$ & -0.05 & $(0.91)$ & & \\
Sex & 0.55 & 0.50 & 0.01 & $-0.22^{* * *}$ & $0.12^{* *}$ & $0.15^{* * *}$ & - & \\
Race & 0.84 & 0.37 & $0.16^{* * *}$ & $0.28^{* * *}$ & $0.17^{* * *}$ & 0.05 & -0.03 & -
\end{tabular}

Notes: $n=528$. Sex $(0=$ female, $1=$ male); race $(0=$ non-white, $1=$ white $)$. For all continuously measured variables, higher scores indicate higher levels of the variable measured. ${ }^{*} p<0.05$; $* * p<0.01,{ }^{* * *} p<0.001$ 


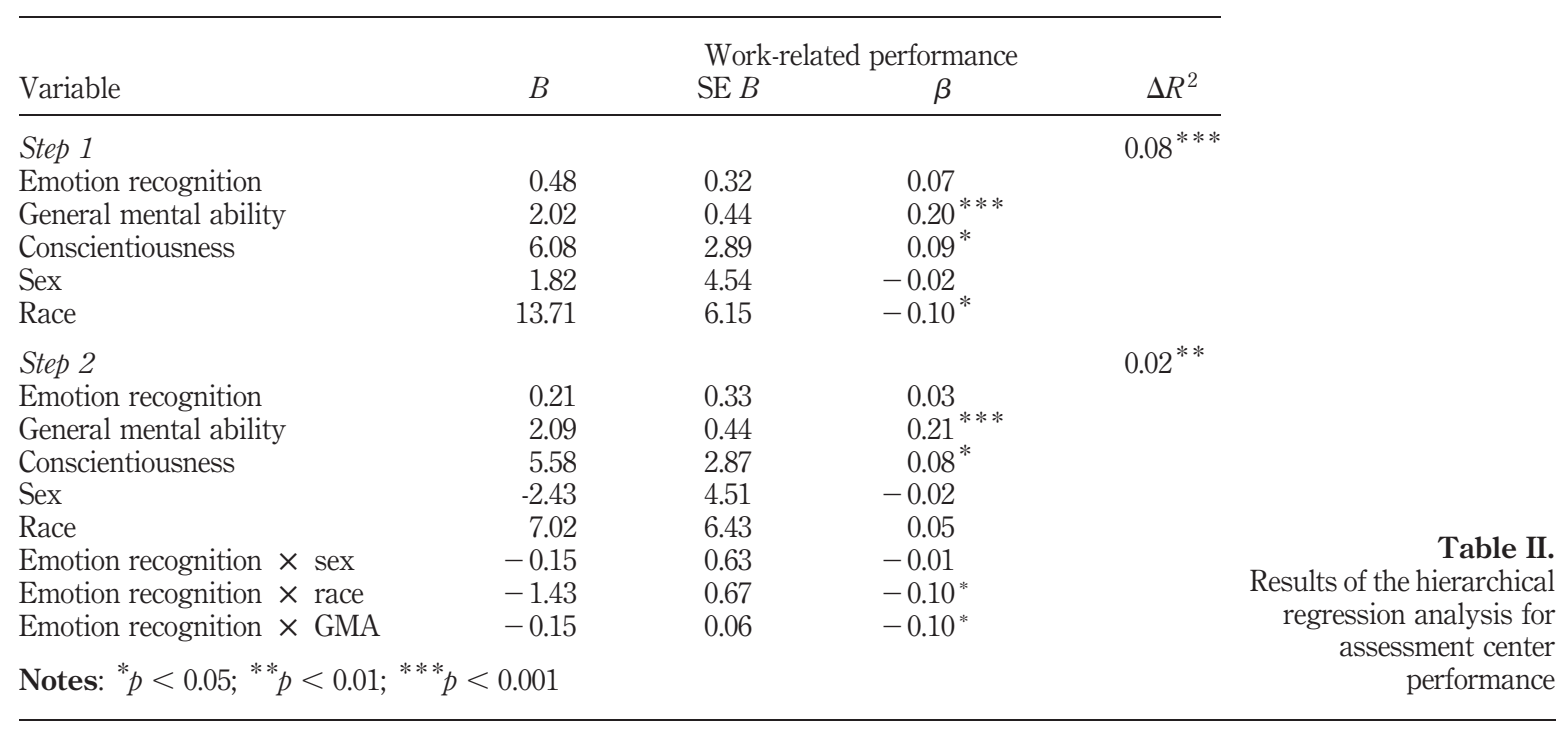

To test $H 2, H 3$ and $H 4$, we inspected the regression coefficients for the respective interaction terms. Contrary to $\mathrm{H} 2$, sex did not moderate the relationship between emotion recognition and work-related performance, but consistent with $H 3$ and $H 4$, both race and GMA, respectively, moderated the relationship between emotion recognition and assessment center performance.

To determine whether the form of the interactions were consistent with our hypotheses, we ran split-plot models as recommended by Aiken and West (1991). First, we ran two regression models, one for white participants $(n=438)$ and one for non-white participants $(n=90)$. In each model, we regressed assessment center performance on GMA, conscientiousness, and emotion recognition. We then examined the statistical significance of the regression coefficient for participants' emotion recognition skill within each group to determine whether the relation between their skill level and assessment center performance was moderated by race.

The results revealed a positive relationship between participants' emotion recognition skill and performance for non-white students, but no relationship for white students. Specifically, for non-white participants, emotion recognition was related significantly to assessment center performance $(\beta=0.25, p<0.05)$. However, for white participants, the relationship between emotion recognition and performance was not significant $(\beta=0.00$, n.s.). The results provide support for $H 3$, which predicted that the relationship between emotion recognition and performance would be more positive for non-whites than for whites. The graphs of this interaction can be seen in Figures 1 and 2 .

As shown in Figures 1 and 2, whites, who scored lowest on emotion recognition had the same level of performance as those who scored highest (i.e. 485 in each case). In contrast, non-whites with the lowest score on the test of emotion recognition had a much lower performance level than did non-whites with strong emotion recognition skills (417 vs 495). In sum, emotion recognition skills potentially compensate for perceived status differences between non-white and white groups. 
Figure 1.

The race $x$ emotion recognition interaction for predicting assessment center performance

\section{Figure 2.}

The GMA $\times$ emotion recognition interaction for predicting assessment center performance

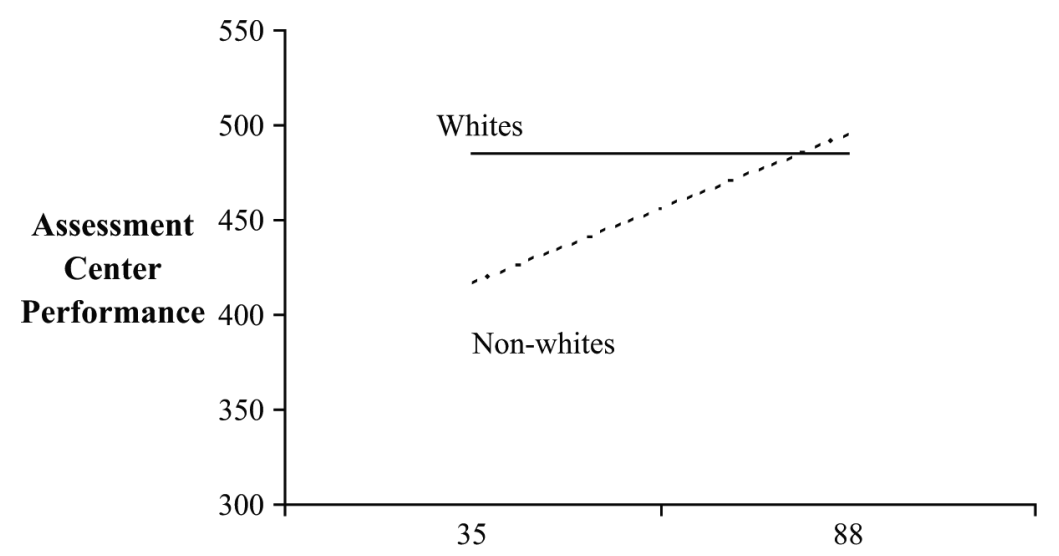

Emotion Recognition (in pct)

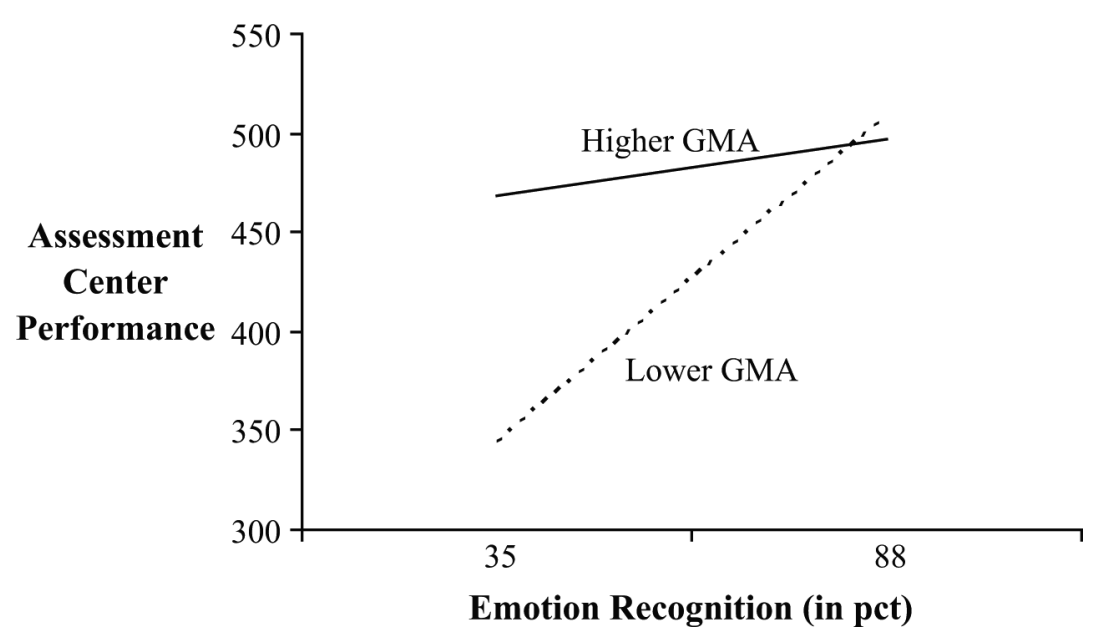

For H4, we examined the interaction between GMA and emotion recognition skills by creating two GMA subgroups ( \pm 1 SD). The high GMA group showed modest improvement in performance when the subjects had strong emotion recognition skills versus weak ones (i.e. 496 vs 469). The low GMA group, however, showed large gains in performance associated with higher emotion recognition skills (509 vs 344). This suggests that for the lower GMA group, emotion recognition skills were highly predictive of good performance, and that possession of these skills may compensate for the effects of lower GMA on performance.

In the current study, participants also completed an in-basket task. We did not include in-basket data in the main analyses, because the task was conducted individually, and did not require emotion recognition skill. The in-basket task primarily is a problem solving activity, loading strongly on GMA (Goldstein et al., 2001). To verify this, we re-ran the previous analyses with the in-basket task as the 
criterion. Here, GMA indeed predicted performance $(\beta=0.33, p<0.001)$, but emotion recognition skill did not $(\beta=-0.01$, n.s.). Further, emotion recognition skill did not interact with sex, race, or intelligence in predicting in-basket performance. It appears that the effects found in the main analyses are not relevant for "g-loaded" individual tasks in which personal interaction is not required.

An additional follow-up analysis examined the relative impact of the performance predictors reported in the study. Overall, GMA, race, and conscientiousness were associated with assessment center performance, but emotion recognition skill and sex were not. The main effects however were masked by interactions with race and GMA. As a result, we ran a series of dominance analyses to determine the relative impacts of the variables of interest. These results can be seen in Table III.

The dominance analysis provided some important information beyond the regression results. When the entire sample was analyzed, GMA was the best predictor of assessment center performance, although the amount of variance it explained was modest (i.e. 8 percent). In contrast (consistent with the regression analysis in Table II), emotion recognition skills are a relatively unimportant part of the picture (offering an impact of less than 15 percent on the small amount of total variance explained).

Table III, however, illustrates that emotion recognition skills are more predictive of assessment center performance in the "low" (i.e. non-white and lower GMA) versus "high" status groups. The predictive models were four times better at explaining assessment center performance for the former (with an average of 18 percent variance explained) versus the latter (with an average of 4.5 percent variance explained). GMA is also considerably less important in predicting performance for non-whites (about 36 percent) versus whites (over 78 percent). Lastly, the dominance analysis also revealed that conscientiousness, while generally not an important predictor of performance overall, was very important for the subgroup with the highest level of GMA.

\section{Discussion}

The present study revealed complex relationships between emotion recognition and assessment-center performance. Moderators included participant race and GMA. Lower status participants on both variables gained significantly more from their emotion recognition skills (in terms of their performance) than did members of the higher status groups.

The idea that sex and race would have an indirect effect on performance was predicated on linking these variables to status. That is, women are perceived to have lower status relative to men, and non-whites are presumed to have lower status relative to whites. Perhaps the failure to find support for the hypothesis predicting that sex had

\begin{tabular}{lccccr}
\hline & & & Subgroup & & \\
Variable & Overall sample & Non-white & White & Lower GMA & Higher \\
\hline GMA & 55.30 & 35.89 & 78.33 & N/A & N/A \\
Conscientiousness & 9.83 & 8.49 & 15.74 & 0.94 & 82.38 \\
Subject sex & 0.76 & 6.54 & 3.52 & 7.74 & 10.00 \\
Subject race & 19.43 & N/A & N/A & 6.38 & 1.43 \\
Emotion recognition & 14.68 & 49.08 & 2.41 & 84.95 & 6.19 \\
Variance explained & 0.08 & 0.16 & 0.05 & 0.20 & 0.04
\end{tabular}

Table III. Results of dominance analysis for assessment center performance 
an indirect effect on performance bodes well for women, suggesting that the status differential between men and women currently of college-age is closing. The lack of sex differences here fits with Snodgrass' work (1985, 1992), which also failed to find differences in emotion recognition after controlling for other status differences.

In contrast, the support for the indirect effect of race is consistent with the subordination hypothesis (Henley, 1977) and other similar hypotheses (e.g. Kirouac and Hess, 1999) presented by theorists of nonverbal behavior (i.e. predicting that advantages will be bestowed on lower status individuals who are better at emotion recognition).

Limitations to the present study include a small sample size for non-white participants. This forced us to collapse across minority groups. Future studies with larger sample sizes could test whether the effects reported here are similar or vary by ethnic minority status. Second, as with many variables in social science, sex, race, and GMA cannot be assigned randomly to participants. Our data do not permit causal inferences with regard to any of the effects we reported. Third, we used a student sample and measured assessment-center (versus job) performance. This raises questions about the study's generalizability to actual work settings. Future research could use a non-student sample and other objective and subjective measures of job performance. Work experience itself might be an important variable moderating the effects reported here. Fourth, the gender status differential could imply that younger women have not felt the status differential as strongly yet, and have not compensated as much as an older female group might. Additional research could assess this and determine if there is a temporal aspect to gender status differential.

The present study offers some implications for management practice specifically, and society, in general. Namely, it provides further support for the predictive validity of emotion recognition in performance contexts. While the predictive validity of emotion recognition for assessment center performance was significantly lower than that of GMA, emotion recognition did explain unique variance. Future research should extend these findings in field studies of actual or potential employees to determine if they can be replicated.

Emotion recognition is considered a primary component of E-IQ. Because emotion recognition skills are learned early in life, they likely form the basis for developing the other, more advanced components of E-IQ (e.g. managing emotions; see Mayer and Salovey, 1997). The results of the present study seem to contradict those who argue that E-IQ is an unqualified predictor of performance (e.g. Goleman, 1998). Indeed, optimism surrounding E-IQ has led some to suggest that measures of the construct should appear in the business school curriculum (Tucker et al., 2000). While the present study did not consider the full array of skills that comprise E-IQ, it did examine one critical and primary component of the construct; emotion recognition. Here we found that emotion recognition skills are not uniformly valuable. Rather, they appear to benefit some groups more than others. Further research should lead to a better understanding of the exact nature and role of skills like emotion recognition as determinants of organizational behavior.

\section{References}

Aiken, L.S. and West, S.G. (1991), Multiple Regression: Testing and Interpreting Interactions, Sage, Newbury Park, CA. 
Barrick, M.R. and Mount, M.K. (1991), "The Big Five personality dimensions and job performance: a meta-analysis", Personnel Psychology, Vol. 41, pp. 1-26.

Bernardin, H.J. and Buckley, M.R. (1981), "Strategies in rater training”, Academy of Management Review, Vol. 6, pp. 205-12.

Brotheridge, C. and Lee, R. (2008), "The emotions of managing: introduction to the special issue", Journal of Managerial Psychology, Vol. 23, pp. 108-17.

Byron, K. (2008), "Differential effects of male and female mangers' non-verbal emotional skills on employees' ratings”, Journal of Managerial Psychology, Vol. 23, pp. 118-34.

Campbell, R.J., Kagan, N. and Krathwohl, D.R. (1971), "The development and validation of a scale to measure affective sensitivity (empathy)", Journal of Counseling Psychology, Vol. 18, pp. 407-12.

Costa, P.T. and McCrae, R.R. (1985), The NEO Personality Inventory Manual, Psychological Assessment Resources, Odessa, FL.

Darwin, C.R. (1872), The Origin of Species by Means of Natural Selection, or the Preservation of Favoured Races in the Struggle for Life, John Murray, London.

Dodrill, C.B. and Warner, M.H. (1988), "Further studies of the Wonderlic Personnel Test as a brief measure of intelligence", Journal of Consulting and Clinical Psychology, Vol. 56, pp. 145-7.

Elfenbein, H.A. and Ambady, N. (2002a), "Predicting workplace outcomes from the ability to eavesdrop on feelings", Journal of Applied Psychology, Vol. 87, pp. 963-71.

Elfenbein, H.A. and Ambady, N. (2002b), "On the universality and cultural specificity of emotion recognition: a meta-analysis", Psychological Bulletin, Vol. 128, pp. 203-35.

Fox, S. and Spector, P.E. (2000), "Relations of emotional intelligence, practical intelligence, general intelligence and trait affectivity with interview outcomes: it's not all just 'G", Journal of Organizational Behavior, Vol. 21, pp. 203-20.

Georgesen, J. and Harris, M.J. (1998), "Why's my boss always holding me down? A meta-analysis of power effects on performance evaluations", Personality and Social Psychology Review, Vol. 2, pp. 184-95.

Goldberg, L.R. (1999), "A broad-bandwidth, public domain, personality inventory measuring the lower-level facets of several five-factor models”, in Mervielde, I., Dreary, I., De Fruyt, F. and Ostendorf, F. (Eds), Personality Psychology of Europe, Vol. 7, Tilburg University Press, Tilburg, pp. 7-28.

Goldstein, H.W., Yusko, K.P. and Nicolopoulos, V. (2001), "Exploring black-white subgroup differences of managerial competencies”, Personnel Psychology, Vol. 54, pp. 783-807.

Goleman, D. (1998), Working with Emotional Intelligence, Bantam Books, New York, NY.

Gottfredson, L. (2003), "g, jobs and life", in Nyborg, H. (Ed.), The Scientific Study of General Intelligence: Tribute to Arthur R. Jensen, Pergamon, New York, NY, pp. 293-342.

Hall, J.A. (2008), “Are women always more interpersonally sensitive than men? Impact of goals and content domain”, Personality and Social Psychology Bulletin, Vol. 34, pp. 144-55.

Heise, D.R. and O’Brien, J. (1993), "Emotion expression in groups", in Lewis, M. and Haviland, J.M. (Eds), Handbook of Emotions, Guilford Press, New York, NY, pp. 489-97.

Henley, N.M. (1977), Body Politics: Power, Sex, and Nonverbal Communication, Prentice-Hall, New York, NY.

Hulsheger, U., Maier, G. and Stumpp, T. (2007), "Validity of general mental ability for the prediction of job performance and training success in Germany: a meta-analysis", International Journal of Selection and Assessment, Vol. 15, pp. 3-18. 
Judge, T., Klinger, R. and Simon, L. (2010), "Time is on my side: time, general mental ability, human capital and intrinsic career success", Journal of Applied Psychology, Vol. 95, pp. 92-107.

Kirouac, G. and Hess, U. (1999), "Group membership and the decoding of nonverbal behavior", in Philippot, P., Feldman, R.S. and Coats, E.J. (Eds), The Social Context of Nonverbal Behavior, Cambridge University Press, New York, NY, pp. 182-210.

McClure, E. (2000), "A meta-analytic review of sex differences in facial expression processing and their development in infants, children, and adolescents", Psychological Bulletin, Vol. 126, pp. 424-53.

McKelvie, S.J. (1989), "The Wonderlic Personnel Test: reliability and validity in an academic setting", Psychological Reports, Vol. 65, pp. 161-2.

Mayer, J.D. and Salovey, P. (1997), "What is emotional intelligence?", in Salovey, P. and Sluyter, D.J. (Eds), Educational Development and Emotional Intelligence: Educational Implications, Basic Books, New York, NY, pp. 3-27.

Nettle, D. (2003), "Intelligence and class mobility in the British population", British Journal of Psychology, Vol. 94, pp. 551-61.

Noller, P. and Feeney, J.A. (1994), "Relationship satisfaction, attachment, and non-verbal accuracy in early marriage", Journal of Nonverbal Behavior, Vol. 18, pp. 199-221.

Nowicki, S. Jr (2000), Manual for the Receptive Tests of the Diagnostic Analysis of Nonverbal Accuracy 2, Department of Psychology, Emory University, Atlanta, GA.

Nowicki, S. Jr and Duke, M.P. (1994), "Individual differences in the nonverbal communication of affect: the diagnostic analysis of nonverbal accuracy scale", Journal of Nonverbal Behavior, Vol. 18, pp. 9-35.

Pesta, B. and Poznanski, P. (2009), "The inspection time and over-claiming tasks as predictors of MBA student performance", Personality and Individual Differences, Vol. 46, pp. $236-40$.

Ridgeway, C.L. and Diekema, D. (1992), “Are gender differences really status differences?”, in Ridgeway, C.L. (Ed.), Gender, Interaction, and Inequality, Springer-Verlag, New York, NY, pp. 157-80.

Riggio, R. and Reichard, R. (2008), "The emotional and social intelligences of effective leadership: an emotional and social skill approach”, Journal of Managerial Psychology, Vol. 23, pp. 1869-85.

Rode, J.C., Arthaud-Day, M.L., Mooney, C.H., Near, J.P., Baldwin, T.T., Bommer, W.H. and Rubin, R.S. (2005), "Life satisfaction and student performance", Academy of Management Journal of Learning and Education, Vol. 4, pp. 421-33.

Rode, J.C., Arthaud-Day, M.L., Mooney, C.H., Near, J.P., Baldwin, T.T., Rubin, R.S. and Bommer, W.H. (2007), "Emotional intelligence and individual performance: evidence of direct and moderated effects", Journal of Organizational Behavior, Vol. 28, pp. 399-421.

Rubin, R.S., Munz, D.C. and Bommer, W.H. (2005), "Leading from within: the effects of emotion recognition and personality on transformational leadership behaviors", Academy of Management Journal, Vol. 48, pp. 845-58.

Ruble, T.L. (1983), "Sex stereotypes: issues of change in the 1970s", Sex Roles, Vol. 9, pp. 397-402.

Sabatelli, R., Buck, R. and Dreyer, A. (1983), "Locus of control, interpersonal trust, and nonverbal communication accuracy", Journal of Personality and Social Psychology, Vol. 44, pp. 399-409.

Salovey, P., Caruso, D. and Mayer, J.D. (2004), "Emotional intelligence in practice”, in Linley, P.A. and Joseph, S. (Eds), Positive Psychology in Practice, John Wiley, Hoboken, NJ, pp. 447-63. 
Saunders, P. (2002), "Reflections on the meritocracy debate in Britain: a response to Richard Breen and John Goldthorpe", British Journal of Sociology, Vol. 53, pp. 559-74.

Schmidt, F. and Hunter, J. (1998), "The validity and utility of selection methods in personnel psychology: practical and theoretical implications of 85 years of research findings", Psychological Bulletin, Vol. 124, pp. 262-74.

Snodgrass, S.E. (1985), "Women's intuition: the effect of subordinate role on interpersonal sensitivity", Journal of Personality and Social Psychology, Vol. 62, pp. 154-8.

Snodgrass, S.E. (1992), "Further effects of role versus gender on interpersonal sensitivity", Journal of Personality and Social Psychology, Vol. 62, pp. 154-8.

Tucker, M.L., Sojka, J.Z., Barone, F.J. and McCarthy, A.M. (2000), “Training tomorrow's leaders: enhancing the emotional intelligence of business graduates", Journal of Education for Business, Vol. 75, pp. 331-6.

\section{Further reading}

Sabatelli, R., Buck, R. and Kenny, D.A. (1986), "A social relations analysis of nonverbal communication accuracy in married couples”, Journal of Personality, Vol. 54, pp. 513-27. 